\title{
BMJ Open Rural general practice patients' coping with hazards and harm: an interview study
}

\author{
Martin Bruusgaard Harbitz, ${ }^{1}$ Helen Brandstorp, ${ }^{2}$ Margrete Gaski ${ }^{2}$
}

To cite: Harbitz MB, Brandstorp H, Gaski M. Rural general practice patients' coping with hazards and harm: an interview study. BMJ Open 2019;9:e031343. doi:10.1136/ bmjopen-2019-031343

- Prepublication history and additional material for this paper are available online. To view these files, please visit the journal online (http://dx.doi. org/10.1136/bmjopen-2019031343).

Received 30 April 2019 Revised 19 August 2019 Accepted 27 September 2019

Check for updates

(C) Author(s) (or their employer(s)) 2019. Re-use permitted under CC BY-NC. No commercial re-use. See rights and permissions. Published by BMJ.

${ }^{1}$ Department of Community Medicine, University of Tromso, Tromso, Norway

${ }^{2}$ Department of Community Medicine, Norwegian Centre for Rural Medicine, University of Tromso, Tromso, Norway

Correspondence to Martin Bruusgaard Harbitz; martin.b.harbitz@uit.no

\begin{abstract}
Objective The aim of this study is to identify and analyse rural general practice patients' experiences of hazards and harm that comprise adverse events, and their strategies for coping with them.

Design Interview study using systematic text condensation and coping strategy theory in an abductive analysis process.

Setting Nine rural general practice clinics in Norway. Participants Twenty participants, aged 21-79 years, all presenting with recent onset of somatic and/or psychiatric complaints.

Results Participating rural general practice patients described their experiences of a variety of hazards and harms. Their three most discussed cognitive and behavioural coping strategies were: (1) to accept the events; (2) to confront them and (3) to engage in planful problem-solving. While the participants demonstrated a tendency toward accepting hazards and harm that their regular general practitioner created, they were often willing to confront those that locum (ie, substitute) general practitioners created. Participants used planful problemsolving in situations they deemed hazardous, such as breaches of confidentiality or not being taken seriously, as well as during potential/actual emergencies.

Conclusions Patients at rural general practice clinics actively identify and respond to hazards and harm, applying three coping strategies. Thus, patients themselves may serve as an important safety barrier against hazards and harm; their potential contributions to improving patient safety must be appreciated accordingly and reflected in future research as well as in everyday clinical practice.
\end{abstract}

\section{INTRODUCTION}

A challenging question regarding patient safety in general practice is how to reduce hazards and avoid harm to patients. In his 'Swiss Cheese model', ${ }^{1}$ James Reason suggested that 'hazards' are local error-producing factors, latent failures, that create conditions for adverse events in healthcare systems. 'Harm' occurs when these conditions breach safety barriers and reach the patients. The responsibility for establishing safety barriers in healthcare systems is assigned to health professionals, health organisations and

\section{Strengths and limitations of this study}

Narrow and purposive sampling within an under-researched rural context.

- Patient-defined hazards and harm.

- Reflexive analyses supported by established theory.

- Questions may arise regarding internal validity of definitions and of retrospective accounts.

- Probability of a cultural effect and a bias appearing when informants seek to please the interviewer.

governments. ${ }^{12}$ The financial and emotional costs of harm are likely to be substantial. ${ }^{34}$

In a Norwegian population study, about $10 \%$ of patients had experienced harm from medical care, for which the general practitioner (GP) was often blamed. ${ }^{5}$ All inhabitants of Norway are entitled to choose their own regular $\mathrm{GP}^{6}$ and over half of Norway's GP clinics can be classified as rural. ${ }^{7}$ In these practices, the GP continuity is often low and frequent use is made of locums (substitute GP) ${ }^{8}$ Patients in rural areas have a lower life expectancy and poorer health status as compared with those in urban areas. ${ }^{9} 10$ Also, rural general practice clinics face such challenges in providing care as: accessibility, limited healthcare services, lack of healthcare providers, and challenges related to distance and transportation. ${ }^{11}{ }^{12}$ Studies of safety in general practice from the patients' perspective have focused on suburban or urban populations that are frequent GP users, have chronic conditions and are elderly, ${ }^{13-17}$ while few studies have focused directly on patients in rural clinical settings. ${ }^{14}$

The field of medicine tends to undervalue and thus overlook the patient's perspective as a resource for patient safety. ${ }^{18}$ Calls are increasing for studies to include patients ${ }^{19} 20$ because patients' experiences, with both perceiving hazards and coping with the aftermath of harm, may provide important insights regarding patient safety. ${ }^{18} 21$ The aim of this study, therefore, is to identify and 
analyse patients' experiences of hazards and harm in rural GP clinics as well as their strategies for coping with them.

\section{METHODS}

\section{Contributors}

The research and author group consisted of one current and one former rural GP (now a researcher) and one senior researcher with a $\mathrm{PhD}$ in health science. We chose a qualitative approach for our study, based on interviews and fieldnotes. We considered face-to-face interviews to be best suited to gaining insight into participants' lived and articulated experiences. ${ }^{22} 23$ All authors contributed to designing, analysing, interpreting and critically revising the manuscript. $\mathrm{MBH}$ performed the interviews in nine different rural GP clinics and kept fieldnotes based on observations and interactions with staff and patients at each GP clinic. The interviews were digitally audiotaped and transcribed verbatim by $\mathrm{MBH}$. We did not seek saturation.

\section{Patient and public involvement}

An interview guide was tested on an ad hoc rural patient advisory group. Pilot interviews were performed with these patients using open-ended questions, deliberately encouraging the patients to introduce their own experiences and whatever topics they considered relevant to the study. This resulted in an interview guide (see online supplementary file) in which we allowed the participants themselves to define hazards, harm and adverse events. The patients did not participate in the design of the study.

The study has followed the Consolidated criteria for Reporting Qualitative research checklist. ${ }^{24}$

We used systematic text condensation inspired by Giorgi's phenomenological thematic cross-case analysis. $^{25}$ Systematic text condensation is a pragmatic method using cross-case analysis to develop new descriptions and concepts of a phenomenon based on the perspective of how they are experienced. ${ }^{26}$ Initially, all researchers read through the data material in its entirety, following the stepwise analysis process of systematic text condensation, ${ }^{26}$ manually coding according to semantic content. One finding was that participants spontaneously emphasised hazardous and harmful events and their own coping. Lazarus theory on coping $^{27}$ was chosen to support the further abductive process using theory both to help us recognise an overarching pattern ${ }^{28}$ and as a 'can opener' ${ }^{29}$ The first of the two processes identified in Lazarus' theory regarding coping involves a cognitive appraisal: do any of the current stressors carry a potential for harm? The second involves a coping appraisal: what might be done to prevent or overcome harm? ${ }^{27}$ Through this process, three themes emerged: (1) participants as active healthcare agents; (2) participants' confronting, hiding or accepting hazards and harm events, but without damaging the participant/GP relationship and (3) participants' acceptance of GP decisions, including the potentially increased travel distance to hospital care.

The next step of our systematic text condensation involved identifying meaning units associated with each theme, and temporarily removing part of the text from its context (decontextualisation). The third and fourth steps (mainly done by $\mathrm{MBH}$ ) involved dividing the themes into subgroups and then making a condensate of suitable meaning units. The three emerging subgroups were: 'the active healthcare agent', 'keep relationships' and 'acceptance'. For the first subgroup, part of the condensate was formulated as follows:

Taking agency in their own health included a range of attitudes and knowledge about their own health, the GP service and potential emergency situations. Some participants had learned to contact the GP service based only on their own suspicion of illness. Others chose to wait as long as possible to see if the symptoms would pass, thus sparing them a GP consultation.

These condensates were then reconceptualised, becoming diverse descriptions and concepts that the research group continued to discuss and reformulate, until agreement on a common understanding had been reached. Participants' statements were anonymised and assigned a random capital letter. We did not perform participant validation.

\section{Recruitment}

Nine of the 12 rural GP clinics that were approached agreed to participate; these ranged from the least to the second-least central municipalities in Norway. ${ }^{7}$ In one municipality, a locum GP refused us access to potential participants. Participants were recruited by healthcare secretaries at the GP clinics' reception counters, as the opportunities presented themselves. Criteria for inclusion were that potential participants be above the age of 18, with a recent onset of a somatic or psychiatric complaint as their presenting problem. Once they agreed to participate, pro bono, participants were given forms to sign confirming that they had received information about the study's focus and their interviewee rights. Since these patients were engaging in a first contact in connection with the recent onset of a clinical issue, they were representatives of a large portion of GP clinic patients and consequently of particular interest. ${ }^{19}$ Their perspectives were likely to differ from those of elderly people with chronic conditions.

\section{Sample}

One telephone interview and 19 face-to-face interviews were conducted between January and April of 2017, immediately following the patients' medical consultations, with each interview lasting an average of $30 \mathrm{~min}$. The face-to-face interviews took place at the local health facility meeting rooms. 


\begin{tabular}{lccll}
\hline $\begin{array}{l}\text { Table } 1 \\
\text { complaints }\end{array}$ & Participant demographics and presenting medical \\
\hline & $\begin{array}{l}\text { 19-29 } \\
\text { years }\end{array}$ & $\begin{array}{l}\text { 30-49 } \\
\text { years }\end{array}$ & $\begin{array}{l}\text { 50-69 } \\
\text { years }\end{array}$ & $\begin{array}{l}>70 \\
\text { years }\end{array}$ \\
\hline Female & 3 & 1 & 5 & 1 \\
\hline Male & 0 & 4 & 2 & 4 \\
\hline $\begin{array}{l}\text { Presenting issue } \\
\text { Respiratory }\end{array}$ & 1 & 0 & 3 & 1 \\
Musculoskeletal & 0 & 1 & 1 & 2 \\
$\begin{array}{l}\text { Psychiatric } \\
\text { Other complaints }\end{array}$ & 0 & 1 & 1 & 0 \\
\hline $\begin{array}{l}\text { Mean number of } \\
\text { chronic diseases }\end{array}$ & 0.3 & 0.8 & 0.6 & 2 \\
\hline
\end{tabular}

\section{RESULTS}

\section{Population}

Participants included 10 women and 10 men, aged 21-79 years, with 53 being their average age. The participant demographics and their reasons for seeking medical help are detailed in table 1. Municipalities varied in size and in travel distance to a hospital, as detailed in box 1. Approximately one-third of the patients who were approached chose not to participate, with lack of time, being too ill or lack of interest being the main reasons mentioned.

\section{Hazards and harm}

Participants identified various hazards they encountered before and during consultations with their regular or locum GP, as well as experiences with harm (see table 2 for an overview). A 53-year-old woman in a rural municipality described the harm she experienced as follows:

I have trouble with gynaecological problems, and so, among other things, I went to see my GP. He took a test, a gynaecological test, that was sent to Troms $\varnothing$, but it really could have been done and looked at under a microscope right here - that wasn't right. $\mathrm{He}$ didn't take any more tests either, so they just figured I had some sort of inflammation and they gave me medicine for that. But it didn't get any better. Then they thought, well, maybe that wasn't such a good idea after all, so I was referred to a gynaecologist in Alta. (L)

Others recounted breaches of medical confidentiality which left them feeling unsafe. For example, one 57-year-old woman was told by her former GP-in public,

\section{Box 1 Distance to the hospital}

- Finnmark county-three municipalities. By car: $179-286 \mathrm{~km}$ to hospital; by boat: 42-65 nautical miles (depending on weather conditions)

- Troms county - three municipalities. By car: $126-165 \mathrm{~km}$ to hospital

- Nordland county-three municipalities. By car: $105-199 \mathrm{~km}$ to hospital
Table 2 Patient-defined hazards and harm in rural general practice

\begin{tabular}{ll}
\hline Hazards & Harm \\
\hline Lack of confidentiality & Wrong medication \\
Communication problems & Delayed diagnosis \\
Disrupted continuity & Wrong diagnosis \\
$\begin{array}{l}\text { Long travel distance and bad } \\
\text { weather }\end{array}$ & $\begin{array}{l}\text { Evoking feelings of } \\
\text { being unsafe }\end{array}$ \\
Patient-doctor relationship issues & Inadequate follow-up \\
GP's clinical skill issues & \\
\hline
\end{tabular}

at the local post office-that her husband needed to quit smoking or else the GP would refuse to continue treating him.

Participants also spoke about communication challenges connected to having to change GPs frequently. At one GP office where locum GPs often filled in for the regular GP, one 79-year-old man who was experiencing newly onset chest palpitations said this about locums and communication:

It's very tiring to have to keep repeating my medical history to a new GP every time. Because of the high use of locums, I trust the GP service less... and I don't speak English well and he [the locum] didn't speak much English at all, and certainly no Norwegian, so we just couldn't communicate. It wasn't possible. (I)

A 'safe' GP was described as someone who knew the patient, the patient's journal, history and work situation. Friendly GPs who knew their patients well were described as 'especially safe'. Such clinical skills and behaviours as performing thorough examinations, asking colleagues for second opinions and ordering blood tests, were mentioned as contributing to the participants' feeling of safety. A 48-year-old man, with a newly discovered and suspicious-looking mole, said that a GP should be honest and curious when speaking with a patient:

A good GP is someone who sees you, really looks at you, and listens to what you have to say. (D)

Many others considered transparency in clinical work to be important, especially when the doctor tested for some diagnosis the patients had not thought of. One 56-year-old man, experiencing a problem with his knee, said:

The doctor should know what he's doing - and let me know what he's doing. (Q)

An 'unsafe' GP was, for example, one who didn't believe the patient, or who needed many consultation visits to take care of a single medical issue. Participants also reported that some GPs seemed more interested in their computers or ultrasonic monitors than in their patients. A 49-year-old man suffering from shoulder pain described it this way: 
I know of GP offices where they don't even take off your coat before they examine you. $(\mathrm{N})$

\section{Coping strategies}

Participants offered a variety of examples of hazards and harm they experienced at rural GP clinics; these were often linked to feeling unsafe. The three most discussed cognitive and behavioural coping strategies were: accepting, confronting and engaging in planful problem-solving. We elaborate on these findings below.

\section{Accept or confront}

Participants expressed that their relationship with the GP impacted whether they accepted or confronted hazards and harm at their GP clinic. In situations where bad weather, long travel distances or lack of treatment continuity presented possible hazards, participants commonly coped by accepting them.

\section{Regarding GP relationships}

Participants described accepting hazards and harm that involved their regular GP. We did encounter examples of participants using a confrontive coping strategy, but those involved locum GPs. Even when their regular GPs made obvious medical errors or caused actual harm, patients stated that they did not choose to initiate a legal process, or even demand that the doctor be placed under supervision, although they were aware both of their right to do so and of whom to contact. Participants explained that they had not contacted someone like the county governor because human error occurs in all professions and their regular GPs were only human, just like them. As one middle-aged woman expressed it:

I just want to say, I'm sure they did the best they could. Everybody can make mistakes, you make mistakes, everybody can. Right? So, you have to understand that. Nobody is perfect. I don't want to, you know, judge them and just dump them. I don't want to be mean.

Another female participant described her regular GP as a local 'king'. Since everyone was dependent on their GP, it was considered dangerous to risk alienating him or her.

One participant recounted an incident when his wife, who suffered from a serious disease, had had her test results overlooked and her symptoms trivialised by their GP, delaying her receiving a proper diagnosis by a full year. Patients rejected the possibility of registering a formal complaint or of starting a process leading to the GP being put under professional supervision, with one pointing out:

We have to keep on living with the same GP, and that's a relationship we don't want to push over the edge. And it's obvious that once we'd trampled all over them, it wouldn't be easy go back there. (E)

Others, not the majority but still quite a few, described utilising more assertive ways of coping. Some switched to GPs in a neighbouring municipality, others to distant, private GP clinics. Some had written a short note detailing their complaints and asked some colleague of the locum GP to pass it on. One man in his 70s suffering from heart palpitations recalled tackling his communication difficulties with foreign locum GPs:

....and I hardly understand a word they [the various locum GPs] say. I got to where I just stood up and left and said: "You should just go home! They can use you there. We don't have any use for you here." They can't even communicate! (E)

\section{Impact of continuity, distance and weather}

Despite preferring to be examined by their own GP, most participants were frequently examined by a foreign locum GP or a GP intern. This was not often reported as problematic. A woman with chest pain said the following about the medical care she received from a locum GP:

Participant: So, I trust him completely and what he found out. I'm sure that, like he said: "If you just take two paracetamols for the pain, you'll manage to relax."

Interviewer: But did he know your story [recurring anxiety and depression] ?

Participant: No, I didn't tell him anything. (B)

Travel time to the nearest hospital of up to $2 \frac{1}{2}$ hours was considered by many participants as being both short and safe. They argued that many people in Norway had just as long or even longer distances to travel. A middleaged woman with dyspnoea said this about rural emergency transportation:

Except for the weather, when the Sea King [search and rescue helicopter] can't land and when the roads are blocked and everything like that, then I think maybe it's not that safe. But we would have to move nearer to a hospital and go and live there if we were going to be afraid of that kind of stuff. (M)

\section{Planful problem-solving}

This coping strategy was invoked frequently and emphatically when participants felt their health problems were not being taken seriously, or when they felt they were faced with potential emergency situations.

\section{Caring for one's own health}

All participants demanded that the GPs take the patients' concerns seriously. They described how they had arrived with written lists of what they wanted to discuss. One participant in her 40s described how she insisted that the GP contact the local hospital for a second opinion:

If you have been sick a lot like I have, I know I can make certain demands. I can say [to the GP]: Listen. Just go call the local hospital and hear what they think. (T) 
Many also stressed the importance of receiving updated information about their health status and medical findings. As one woman in her 20 s, who had an upper respiratory infection, put it:

I think that you have some responsibility too, if you have the chance to inform yourself about your own illness. I don't mean trying to be your own internet GP. But just find out a little about it; yes, know yourself, and the mechanisms behind your illness. $(G)$

We also found examples in municipalities with a high turnover of locum GPs where participants had to take responsibility for their own adherence to treatment guidelines. A man with cancer, following several prior myocardial infarcts, said this about the follow-up routines:

I watch out for myself. I have to. I have to make sure I come down here [to the GP's office] because nobody is going to call me in for a check-up. (E)

\section{In emergency situations}

At their own initiative, participants from all the municipalities brought up the theme of emergency awareness and preparedness. They were familiar with their local emergency facilities and often with alternate means of transportation as well, such as the large passenger ferry that would be converted into an ambulance boat during periods of extreme weather. A 45-year-old woman described her emergency preparedness in this way:

....and when the Emergency Medical Communication Centre [EMCC] at Hammerfest doesn't answer, who do you call? Well, then you call the EMCC at Bodø. Because, sometimes, that's how it's been for me. (T)

A man who lived on a small island without a local GP said this about emergency awareness:

My father was actually the one who brought a defibrillator to this island. It's hanging on the wall at the local store in case something happens... and when it came, they [the store's employees] got trained how to use it. $(\mathrm{N})$

\section{DISCUSSION}

Our findings highlight rural general practice clinic patients' experiences of hazards and harm that comprise adverse events, and address some of the ways they cope with them. Patients' experiences broadly align with existing empirical literature regarding patients' perspectives on patient safety, highlighting the human elements of safety: a subjective and nuanced construction based on good communication. ${ }^{430} 31$

We add new evidence documenting how patients use coping strategies in relation to perceived hazards and in the aftermath of harm, and we argue that patients' experiences must be acknowledged and integrated into medical safety practice as well as into ongoing and future research.

The patients' experiences of hazards and harm, and the ways they cope with them described herein are consistent with the two-step cognitive model for stress management and coping strategies. ${ }^{27}$ Participants described how they first assessed safety threats (cognitive appraisal) and then chose cognitive or behavioural responses to these threats (coping). Participants seemed to accept hazards and harm experiences that had been caused by their regular GP, arguing both that human errors are understandable and that having a good relationship with their GP is important. In cases of harm or error, participants refrained from initiating legal action or demanding that the GP be placed under professional supervision. Thus, coping was shaped by both personal resources and contextual determinants. ${ }^{32}$ This could indicate that patients are aware of both the contextual and the interpersonal reasons for not taking legal action. We encountered participants who did not passively accept a hazard or harm created by locum GPs, but rather confronted the experience and the practitioner, directly or indirectly. In Norway, locum GPs are often on short employment contracts (weeks) with decreased centrality and population size correlating to the duration of the contract. ${ }^{8}$ Perhaps that lack of continuity leaves room for patients to be more critical and less concerned with establishing and maintaining a quality patient-doctor relationship.

According to James Reason's Swiss Cheese metaphor, safety barriers (so called cheese slices) have unintended weaknesses-holes. When such holes align, hazards are able to pass through and cause patients harm. ${ }^{1}$ Mapping our findings onto the safety barriers described in Reason's Swiss Cheese model ${ }^{1}$ highlights how patients' coping with these hazards may function as safety barriers (see figure 1). Our findings suggest that patients themselves may both function and act as safety barriers against harm; this challenges the standard models, in which safety barriers are perceived as being external factors. ${ }^{12}$ Our data also support the idea of including patients in the designing and developing of safety barriers in order to incorporate personal and contextual aspects into improvements to general practice. ${ }^{33}$ This complements the contribution which good communication and person-centred healthcare make to helping patients feel and be safe $^{4}$ and opens for potential patient contributions to improving and operationalising safety in general practice. ${ }^{19}$ Feedback from various patients indicates that many of them had accepted hazards and harm without their GP's knowledge. Consequently, encouraging GPs to ask their patients for feedback about hazards and harmroutinely and systematically-might improve both patients' and GPs' ability to collaborate as well as increase the safety of current and future care. We believe patients' narratives about hazards represent a rich resource for improving GPs' clinical behaviour, increasing their awareness of their own biases ${ }^{34}$ and how they think intuitively. ${ }^{35}$ We question whether narratives from unknown patients 


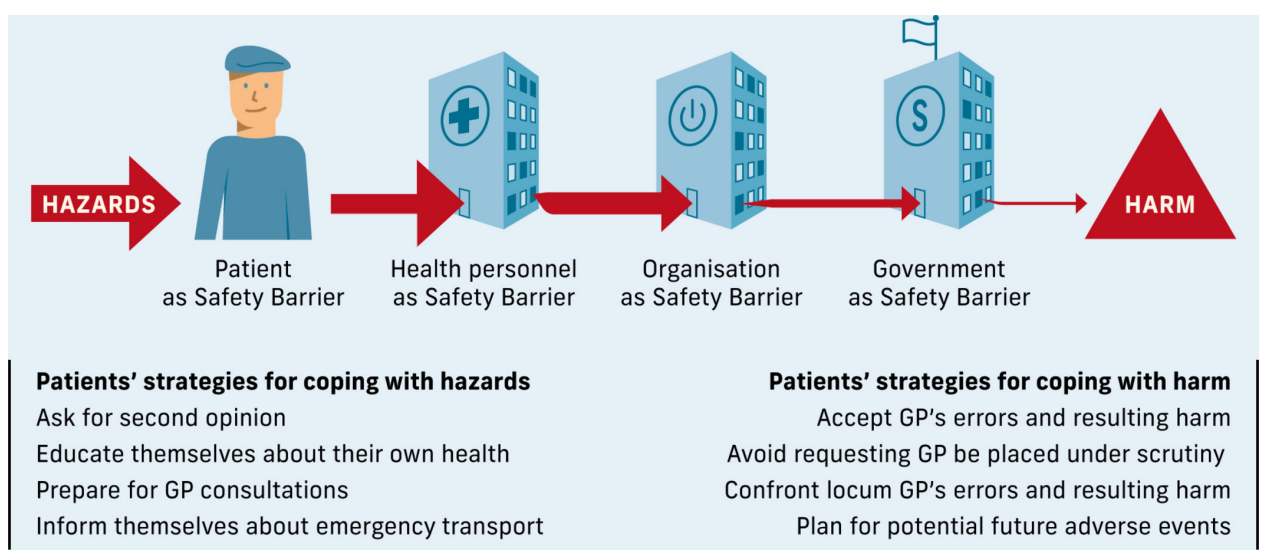

Figure 1 Patients as safety barriers against hazards in general practice.

could offer the same potential ${ }^{36}$ for learning as do those from one's own patient group. Encouraging the inclusion of patients as safety barriers in healthcare and in the design of future studies, using qualitative and/or quantitative designs, may also deepen insight regarding larger and more representative populations.

The strengths of this study include its close-up, patient-focused data, its narrowly defined and purposive sampling, its clear study aim utilising reflexive analysis and supported by established theory. Excluding patients with chronic disease complaints allowed us to focus on newly ill patients; though they are frequent users of rural GP services and constitute an important population, ${ }^{37}$ they have been the focus of far fewer studies. Although only the least and second-least central municipalities were chosen for inclusion in the study, these represent a level of centrality shared by over $50 \%$ of Norway's municipalities, based on the established index. ${ }^{7}$ We did not define hazard, harm, error, patient safety or adverse events for the patients in our study, but rather allowed them to apply their own interpretations of their meaning. Presenting patients with set definitions of concepts and words would have limited the range of potential meanings the patients could discover and present to us. Also, conducting the interviews immediately after GP consultations allowed us to document the patients' spontaneous reactions and reflections; this helped to prevent recollection bias from distorting their reports. It may also have helped to deepen the patients' perspectives by bringing memories of prior GP clinical setting experiences of hazards and harm to their awareness.

It is plausible that questions may arise regarding internal validity of concept and word definitions, as well as of retrospective accounts. The method and sampling might increase the probability of a context effect and a bias $^{23}$ arising when informants want to please the doctor. Based on the methods, ${ }^{22}$ the complexity of general practice $^{38}$ and the diversity of patients and GP clinics, it is difficult to claim a generalisability for our findings. Another important consideration is the first author's prejudices, and the standard of reflexivity during the interviews and analysis ${ }^{23}$ as he himself is a rural GP, interested in patient-centred communication and in safety.

\section{CONCLUSION}

The exploration of patients' experiences and coping strategies reveals that rural GP clinic patients actively identify and respond to hazards and harm. We have identified three coping strategies that patients use. Thus, patients themselves may serve as an important safety barrier, contributing to improving patient safety. Their contribution must be appreciated accordingly and reflected in future research.

\section{Twitter Martin Bruusgaard Harbitz @martin_harbitz}

Acknowledgements The authors wish to thank the participants and the GP clinics that contributed to this study. We also thank graphic designer Torger Grytå for his help developing figure 1 and to Susan S Senstad for perceptive language editing.

Contributors All authors contributed to the conception of the article and analysis and interpretation of the results. Study design: MBH, HB, MG; data acquisition: $\mathrm{MBH}$ and drafting the manuscript: $\mathrm{MBH}, \mathrm{HB}, \mathrm{MG}$. Reviewing and critically revising the final version of the manuscript: $M B H, H B, M G$. MBH finalised and submitted the manuscript. $\mathrm{MBH}, \mathrm{HB}$ and $\mathrm{MG}$ replied to reviewers' comments and amended the manuscript accordingly.

Funding The project was funded by The Norwegian Centre of Rural Medicine, Program for Rural Medical Research and Development ('Programmet') and the Norwegian Research Fund for General Practice. This article's publication expenses have been covered by a grant from the publication fund of UiT The Arctic University of Norway.

\section{Competing interests None declared.}

Patient consent for publication Not required.

Ethics approval The study was approved by the Regional Committee for Medical and Health Research Ethics (2016/2314 REK Nord) and conducted according to the guidelines of the Norwegian Centre for Research Data (project \# 52557) assuring anonymity and data protection.

Provenance and peer review Not commissioned; externally peer reviewed. Data availability statement Data are available upon reasonable request.

Open access This is an open access article distributed in accordance with the Creative Commons Attribution Non Commercial (CC BY-NC 4.0) license, which permits others to distribute, remix, adapt, build upon this work non-commercially, and license their derivative works on different terms, provided the original work is properly cited, appropriate credit is given, any changes made indicated, and the use is non-commercial. See: http://creativecommons.org/licenses/by-nc/4.0/.

\section{REFERENCES}

1 Reason J. Human error: models and management. BMJ 2000;320:768-70. 
2 Samra R, Car J, Majeed A, et al. How to monitor patient safety in primary care? healthcare professionals' views. JRSM Open 2016;7:2054270416648045

3 Jha AK, Larizgoitia I, Audera-Lopez C, et al. The global burden of unsafe medical care: analytic modelling of observational studies. BMJ Qual Saf 2013;22:809-15.

4 Daker-White G, Hays R, McSharry J, et al. Blame the patient, blame the doctor or blame the system? A meta-synthesis of qualitative studies of patient safety in primary care. PLoS One 2015;10:e0128329.

5 Hotvedt R, Førde OH. Doctors are to blame for perceived medical adverse events. A cross sectional population study. The Troms $\varnothing$ study. BMC Health Serv Res 2013;13:46.

6 Ministry-of-Health-and-Care-Services. Regulation relating to a municipal regular GP scheme Oslo Oslo, 2000. Available: https:// www.regjeringen.no/en/dokumenter/regulation-relating-to-amunicipal-regul/id420530/ [Accessed 13 Jun 2018].

7 Høydahl E. New centrality index for the municipalities: Statistics Norway, 2017. Available: https://www.ssb.no/befolkning/artikler-ogpublikasjoner/_attachment/330194?_ts=15fdd63c098

8 Abelsen B, Gaski M, Brandstorp H. The regular GP scheme in municipalities with less than 20000 inhabitants, 2016.

9 Strasser R, Kam SM, Regalado SM. Rural health care access and policy in developing countries. Annu Rev Public Health 2016;37:395-412.

10 International Labour Organization. UN. Global evidence on inequities in rural health protection: new data on rural deficits in health coverage for 174 countries. In: Scheil-Adlung X, ed. Ess document no 47. Geneva International Labour Office, 2015.

11 AWe JK. Health in Rural Canada. In: . Vancouver: Press U, 2011.

12 Murphy P, Burge F, Wong ST. Measurement and rural primary health care: a scoping review. Rural Remote Health 2019;19:4911.

13 Hernan AL, Giles SJ, Fuller J, et al. Patient and carer identified factors which contribute to safety incidents in primary care: a qualitative study. BMJ Qual Saf 2015;24:583-93.

14 Hernan AL, Walker C, Fuller J, et al. Patients' and carers' perceptions of safety in rural general practice. Med J Aust 2014;201:60-3.

15 Mira JJ, Nebot C, Lorenzo S, et al. Patient report on information given, consultation time and safety in primary care. BMJ Qual Saf 2010;19:e33.

16 Pandhi N, Schumacher J, Flynn KE, et al. Patients' perceptions of safety if interpersonal continuity of care were to be disrupted. Health Expect 2008;11:400-8.

17 Rhodes P, Campbell S, Sanders C. Trust, temporality and systems: how do patients understand patient safety in primary care? A qualitative study. Health Expect 2016;19:253-63.

18 King A, Daniels J, Lim J, et al. Time to listen: a review of methods to solicit patient reports of adverse events. Qual Saf Health Care 2010;19:148-57.

19 Verstappen W, Gaal S, Bowie P, et al. A research agenda on patient safety in primary care. Recommendations by the LINNEAUS collaboration on patient safety in primary care. Eur J Gen Pract 2015;21:72-7.

20 Institute, of, Medicine. Crossing the quality chasm: a new health system for the 21 st century. Washington, DC: National Academy Press, 2001: 71-3.

21 Trier $\mathrm{H}$, Valderas JM, Wensing $\mathrm{M}$, et al. Involving patients in patient safety programmes: a scoping review and consensus procedure by the LINNEAUS collaboration on patient safety in primary care. Eur $J$ Gen Pract 2015;21:56-61.

22 Kvale S, Brinkmann S, Anderssen TM, et al. The qualitative research interview. 3. utg., 2. oppl. Oslo: Gyldendal akademisk, 2015.

23 Malterud K. Qualitative research: standards, challenges, and guidelines. Lancet 2001;358:483-8.

24 Tong A, Sainsbury P, Craig J. Consolidated criteria for reporting qualitative research (COREQ): a 32-item checklist for interviews and focus groups. Int J Qual Health Care 2007;19:349-57.

25 Giorgi A. The descriptive phenomenological method in psychology: a modified Husserlian approach. Pittsburgh, Pa: Duquesne University Press, 2009.

26 Malterud K. Systematic text condensation: a strategy for qualitative analysis. Scand J Public Health 2012;40:795-805.

27 Lazarus RS, Folkman S. Stress, appraisal, and coping. New York: Springer, 1984

28 Alvesson M, Sköldberg K. Reflexive methodology: new vistas for qualitative research. 2nd ed. London: Sage, 2009.

29 Høyer K. What is theory, and how to relate to theory? research methods in public health science. København: Munksgård, 2012: 17-41.

30 Rhodes P, McDonald R, Campbell S, et al. Sensemaking and the co-production of safety: a qualitative study of primary medical care patients. Sociol Health IIIn 2016;38:270-85.

31 Ricci-Cabello I, Pons-Vigués M, Berenguera A, et al. Patients' perceptions and experiences of patient safety in primary care in England. Fam Pract 2016;33:535-42.

32 Aldwin CM. Stress, coping, and development: an integrative perspective. 2nd ed. New York: Guilford Press, 2007.

33 Lamont T, Waring J. Safety lessons: shifting paradigms and new directions for patient safety research. $J$ Health Serv Res Policy 2015;20:1-8.

34 Croskerry P, Singhal G, Mamede S. Cognitive debiasing 1: origins of bias and theory of debiasing. BMJ Qual Saf 2013;22:ii58-64.

35 Kahneman D. Thinking, fast and slow. New York: Farrar, Straus and Giroux, 2011.

36 Jha V, Buckley $\mathrm{H}$, Gabe R, et al. Patients as teachers: a randomised controlled trial on the use of personal stories of harm to raise awareness of patient safety for doctors in training. BMJ Qual Saf 2015;24:21-30.

37 Hunskår S, ed. General practice. Oslo: Gyldendal Akademiske, 2013.

38 Sturmberg JP, Martin CM, Katerndahl DA. Systems and complexity thinking in the general practice literature: an integrative, historical narrative review. Ann Fam Med 2014;12:66-74. 